\title{
Palladium-catalyzed selective activation of allyl alcohols as allyl cations, allyl anions, and zwitterionic trimethylenemethanes*
}

\author{
Yoshinao Tamaru‡ and Masanari Kimura \\ Department of Applied Chemistry, Faculty of Engineering, Nagasaki University, \\ 1-14 Bunkyo, Nagasaki 852-8521, Japan
}

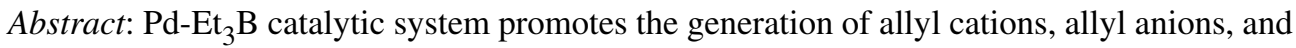
zwitterionic trimethylenemethane species from the corresponding allylic alcohols. Allyl cations react with a wide variety of nucleophiles, e.g., amines, active methylene compounds, 1,3,5-trihydroxybenzene, indoles, aldehydes (at the $\alpha$-position). The reaction is extended to dehydrative Grob fragmentation of 1,3-diols. Allyl anions react with aldimines to give homoallyl amines. Zwitterionic trimethylenemethane, generated from 2-methylene-1,3-propanediol, reacts with aldehydes and aldimines to provide 3-methylenecyclopentanols and 3-methylenepyrrolidines, respectively. Vinyl epoxide can be utilized as a synthetic equivalent of 3-butenyl 2-anion-1-cation.
\end{abstract}

Keywords: allyl alcohols; allyl anions; allyl cations; catalysis; palladium; triethylborane; trimethylenemethane; umpolung.

\section{INTRODUCTION}

Allylation reactions, both electrophilic (allylation at the $\alpha$-carbons of carbonyls and heteroatoms) and nucleophilic (allylation at the carbonyl carbons) are among the most reliable and useful processes to elaborate molecules into the desired compounds. The ability of hydroxy group as a leaving group is such that electrophilic allylation has been generally performed by converting allyl alcohols into allyl halides (step 1, Scheme 1). In order to perform nucleophilic allylation, a further transformation of allyl halides into allylmetals or allylmetalloids is necessary (step 2, Scheme 1).

This paper describes that both electrophilic and nucleophilic allylations can be performed directly by using allyl alcohols under the catalysis of palladium in the presence of triethylborane $\left(\mathrm{Et}_{3} \mathrm{~B}\right)$. This catalytic process is advantageous over the existing methods in many respects (Scheme 1). For example, we can save one step (e.g., halogenation) for the generation of allyl cations and also we can save two steps for the generation of allyl anions. We can avoid the use of acids, bases, metals, and metalloid species. No strictly dry conditions are necessary; in fact, one molecule of water is produced in every one catalytic cycle for the generation of allyl cations and anions. Furthermore, by the combination of these two methods, zwitterionic trimethylenemethane species I can be generated from 2-methylene-1,3propanediol (Scheme 1) [1].

\footnotetext{
*Paper based on a presentation at the $14^{\text {th }}$ International Symposium on Organometallic Chemistry Directed Towards Organic Synthesis (OMCOS-14), 2-6 August 2007, Nara, Japan. Other presentations are published in this issue, pp. 807-1194.

¥Corresponding author
} 

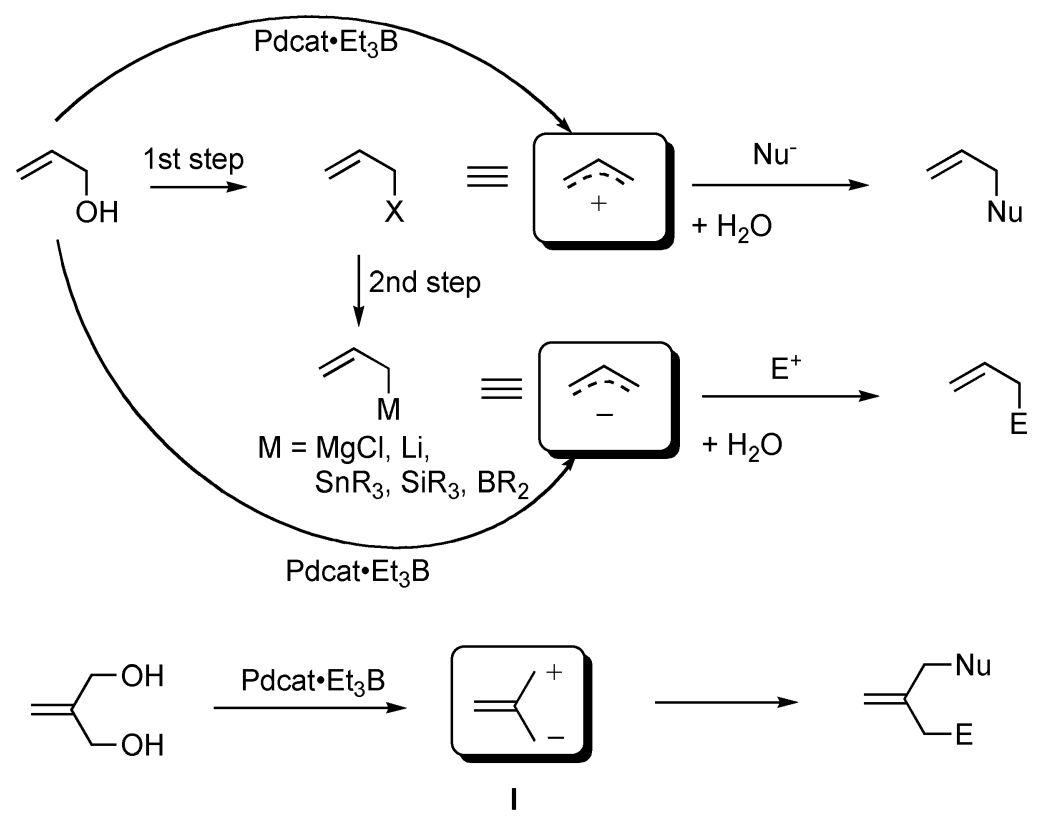

Scheme 1 Direct generation of allyl cations, allyl anions, and zwitterionic trimethylenemethane I from allyl alcohols catalyzed by Pd.

Scheme 2 outlines the basic strategy for the direct activation of allyl alcohols catalyzed by $\mathrm{Pd}$ and $\mathrm{Et}_{3} \mathrm{~B}$. Here, $\mathrm{Et}_{3} \mathrm{~B}$ works in two ways. First, by coordination to the hydroxy group, $\mathrm{Et}_{3} \mathrm{~B}$ activates an allyl alcohol toward oxidative addition of $\mathrm{Pd}(0)$ upon the allylic $\mathrm{C}-\mathrm{O}$ bond. $\pi$-Allylpalladium II may serve as an allyl cation if some appropriate nucleophiles are present, regenerating a catalytically active $\operatorname{Pd}(0)$ species and $\mathrm{Et}_{3} \mathrm{~B}$, at the same time, generating one molecule each of an expected allylation product and water.

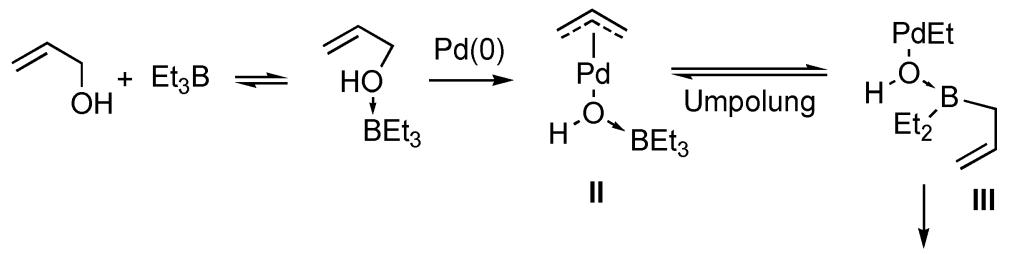

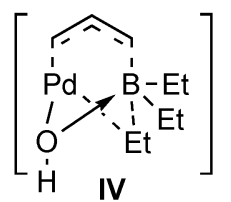

$$
\begin{aligned}
& +\mathrm{Pd}(\mathrm{O})+\mathrm{CH}_{2}=\mathrm{CH}_{2}+\mathrm{H}_{2} \mathrm{O}
\end{aligned}
$$

Scheme 2 Mechanistic outline for the Pd-catalyzed generation of allyl cation and anion from allyl alcohol.

In the absence of any nucleophiles, then, $\mathrm{Et}_{3} \mathrm{~B}$ may start to play the second role and promote the exchange reaction of ethyl group and allyl group of the $\pi$-allylpalladium II probably through a transition state IV and provide an intermediate III. Along with decomposition of ethylpalladium moiety of III into Pd(0), ethylene and water, III may be converted into allyldiethylborane [2]. That is, through these processes, umpolung of an allyl cation into an allyl anion may be established. 
It should be noted that the same catalytic system, $\mathrm{Pd}(0)-\mathrm{Et}_{3} \mathrm{~B}$, works for the generation of both allyl cations and allyl anions. The reaction features completely depend on the reaction partners. When an appropriate nucleophile is present, allyl alcohols work as allyl cations through II. On the other hand, in the absence of nucleophiles and in the presence of electrophiles, allyl alcohols will have an opportunity to work as allyl anions through allylboranes.

\section{GENERATION OF ALLYL CATION}

N-Allylation of amines with allyl alcohols takes place readily in the presence of catalytic amounts of $\mathrm{Pd}(\mathrm{OAc})_{2}$ and $\mathrm{Et}_{3} \mathrm{~B}$ (Scheme 3) [3]. In order to perform the reaction successfully, the choice of phosphine ligand is crucial. For the allylation of aliphatic amines, tributylphosphine is the best ligand. For the allylation of aromatic amines, triphenylphosphine is the best ligand. Under these conditions, we can obtain $\mathrm{N}$-allylation products in excellent yields for a variety of amines.

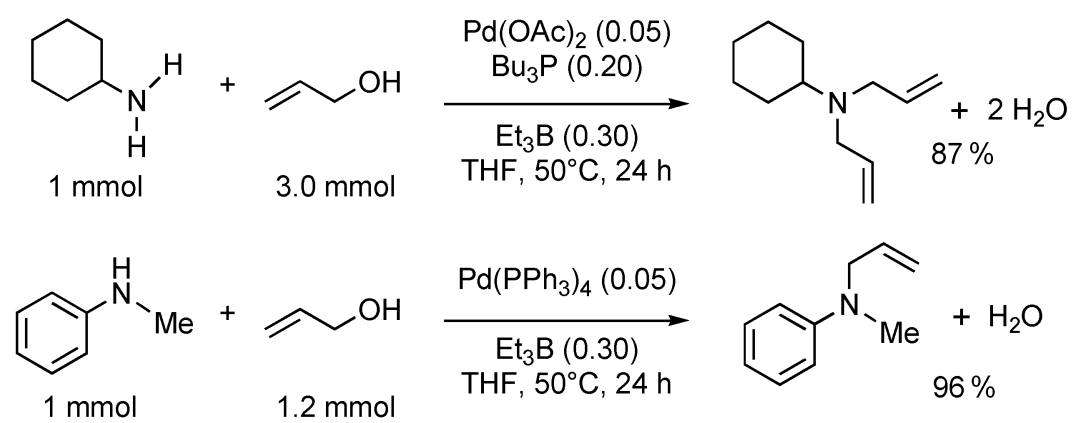

Scheme 3 N-Allylation of amines with allyl alcohols catalyzed by $\operatorname{Pd}(0)-\mathrm{Et}_{3} \mathrm{~B}$ catalyst system.

C-Allylation of active methylene compounds (diethyl malonate, 2-ethyoxycarbonylcyclohexanone, acetylacetone, 2-acetylcyclohexanone, 2-formylcyclohexanone, etc.) can be performed with similar ease [4]. For example, $\alpha$-acetyl- $\gamma$-butyrolactone undergoes allylation with parent allyl alcohol and its derivatives bearing substituents $\alpha-, \beta-$, and/or $\gamma$-positions (Scheme 4).

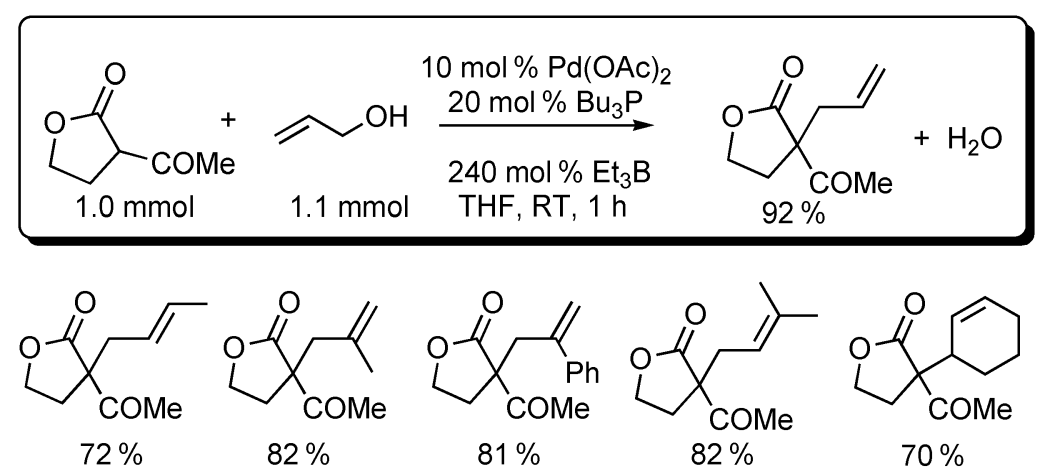

Scheme 4 C-Allylation of $\alpha$-acetyl- $\gamma$-butyrolactone with a variety of allyl alcohols catalyzed by $\operatorname{Pd}(0)-\mathrm{Et}_{3} \mathrm{~B}$ catalyst system. 
The hexa-allylation of benzenetriol may be of great interest, not only because of the efficiency of the reaction that can be achieved with only $5 \mathrm{~mol} \%$ of Pd catalyst, but also because of the unique structure of the product (Scheme 5) [5]. This product with high symmetry is rich in double bond and may be used as a linker of polymers and for the synthesis of dendrimers and functional materials.<smiles>C=CCO</smiles>

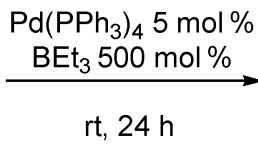

$\mathrm{rt}, 24 \mathrm{~h}$

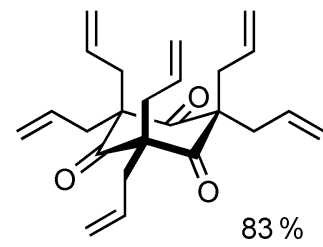

Scheme 5 Hexa-allylation of benzenetriol with allyl alcohol under neutral conditions.

Already almost one century ago, hexa-methylation of benzenetriol was examined under alkaline conditions [6]. Despite many trails, changing the concentration of $\mathrm{KOH}$, the reaction temperatures, and the amounts of MeI, the expected product was never obtained in good yield (Scheme 6).

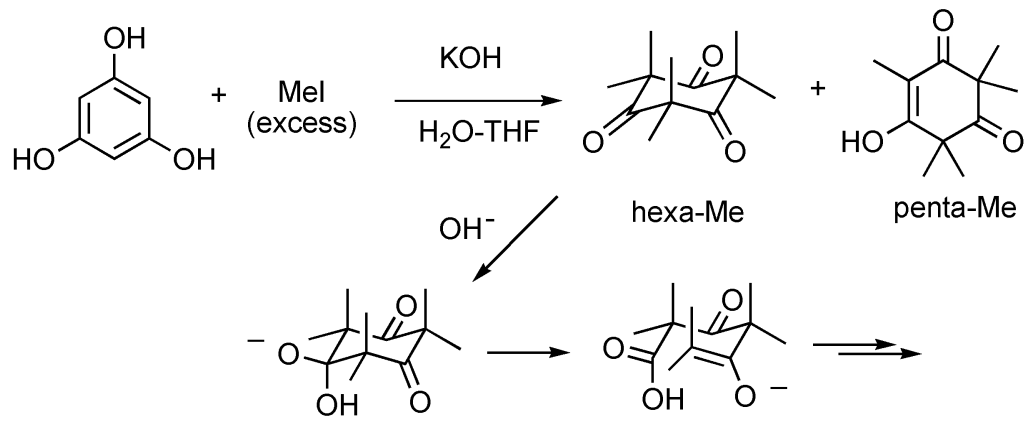

Scheme 6 Retro-aldol/ring-opening of hexa-methylation product of benzenetriol under alkaline conditions.

In the light of today's chemical knowledge, this failure may be attributed to the retro-aldol of the hexa-methylation product under alkaline conditions which causes ring-opening and many side reactions. In this context, our success of hexa-allylation is remarkable, and the success may be attributed to the mild reaction conditions undertaken at room temperature and especially under neutral conditions [7].

Indole is an ambident nucleophile (at $\mathrm{N}$ and $\mathrm{C} 3$ ), however, it underwent allylation selectively at $\mathrm{C} 3$ position under our conditions using 1 equiv of allyl alcohol and $\mathrm{Pd}\left(\mathrm{PPh}_{3}\right)_{4}$ and $\mathrm{Et}_{3} \mathrm{~B}$ both in a catalytic amount (Scheme 7) [8]. Among many indole derivatives examined, 2-Me indole was exceptionally unreactive and required long heating. In sharp contrast, 3-Me indole was very reactive and the reaction was complete within $2 \mathrm{~h}$. It should be noted that electron-deficient 5-nitroindole is more reactive than electron-rich 5-methoxy and 5-hydroxyindoles. At the moment, we cannot rationalize this contrasting reactivity.

The reaction of 3-methylindole creating a quaternary carbon center is extended successfully to asymmetric allylic alkylation by Trost, which shows up to $85 \%$ ee [9]. 


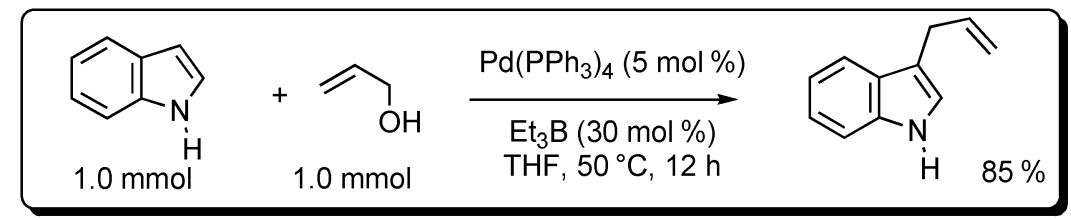<smiles>C=CCc1c(C)[nH]c2ccccc12</smiles>

$70 \%(70 h)$<smiles>C=CCC1(C)C=Nc2ccccc21</smiles>

$75 \%(2 h)$<smiles>[R]Oc1ccc2[nH]cc(CC=C)c2c1</smiles>

$\mathrm{R}=\mathrm{Me}: 77 \%(23 \mathrm{~h})$ $\mathrm{R}=\mathrm{H}: \quad 96 \%(24 \mathrm{~h})$<smiles>C=CCc1c[nH]c2cccc(Br)c12</smiles>

$84 \%(24 h)$<smiles>C=CCc1c[nH]c2ccc([N+](=O)[O-])cc12</smiles>

$86 \%(3 h)$

Scheme 7 C-3 Selective allylation of indoles with allyl alcohols under the catalysis by $\operatorname{Pd}(0)-\mathrm{Et}_{3} \mathrm{~B}$.

Trypthophan methyl ester shows interesting diastereoface selectivity and allylation takes place exclusively from the $\mathrm{Si}$ face at C3 position with concomitant amination at C2 position, providing a pyrroloindole skeleton in good yield (Scheme 8). Selective C-allylation, remaining both aliphatic and aromatic amines unchanged, should be noted.

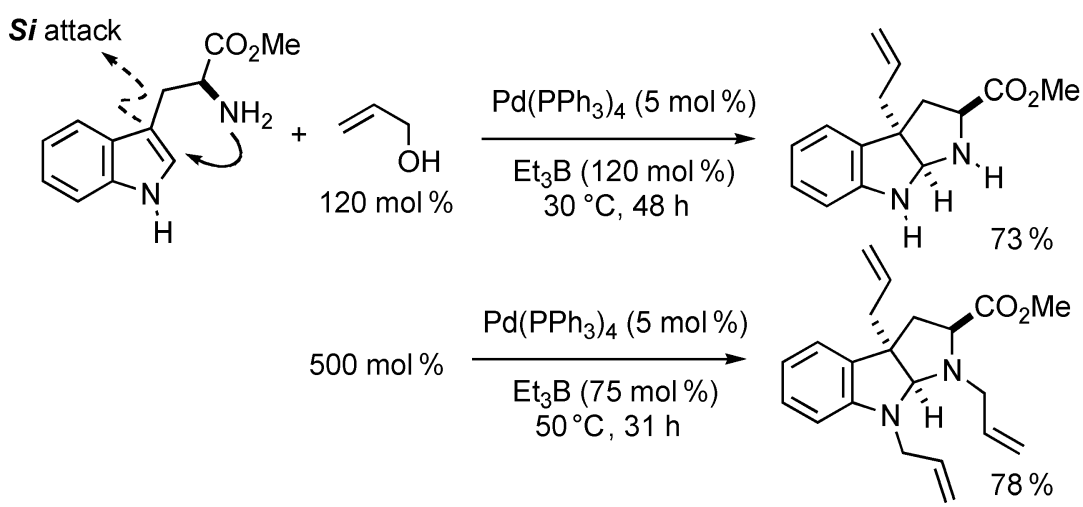

Scheme 8 Diastereoselective mono- and exhaustive allylation of trypthophan methyl ester with allyl alcohol.

By exposing to an excess amount of allyl alcohol, further allylation at both aromatic and aliphatic nitrogen atoms took place and provided a $C, N, N$-tri-allylation product in remarkably good yield (Scheme 8) [10]. This reaction may be useful for the preparation of naturally occurring pyrroloindole alkaloids, such as flustramines A and B [11].

$\alpha$-Allylation of ketones and esters can be performed easily in good yields, however, $\alpha$-allylation of aldehydes is known to be rather difficult. For example, under Pd-catalysis, the $\alpha$-allylation of aldehydes can be only performed successfully by pre-activation of both reaction partners: allyl alcohols as their carbonates and aldehydes as either their silyl enol ethers [12] or enamines [13].

We have succeeded in the $\alpha$-allylation of aldehydes without pre-activation of these reaction partners by slight modification of the reaction conditions described so far, by using $\mathrm{Et}_{3} \mathrm{~N}$ and $\mathrm{LiCl}$ as additives (Scheme 9) [14]. Here, $\mathrm{Et}_{3} \mathrm{~N}$ may serve to generate an aldehyde enolate and $\mathrm{LiCl}$ may serve to retard the conversion of II to III by replacing a $\mathrm{HO}-\mathrm{BEt}_{3}{ }^{-}$anion with $\mathrm{C} \mathrm{Cl}^{-}$anion (Scheme 2).

Secondary aldehydes such as cyclohexanecarbaldehyde, isobutyraldehyde, and $\alpha$-phenylpropionadehyde nicely react with a wide structural variety of allyl alcohols (Scheme 9) [15]. These results clearly indicate the generality and utility of the present method. 

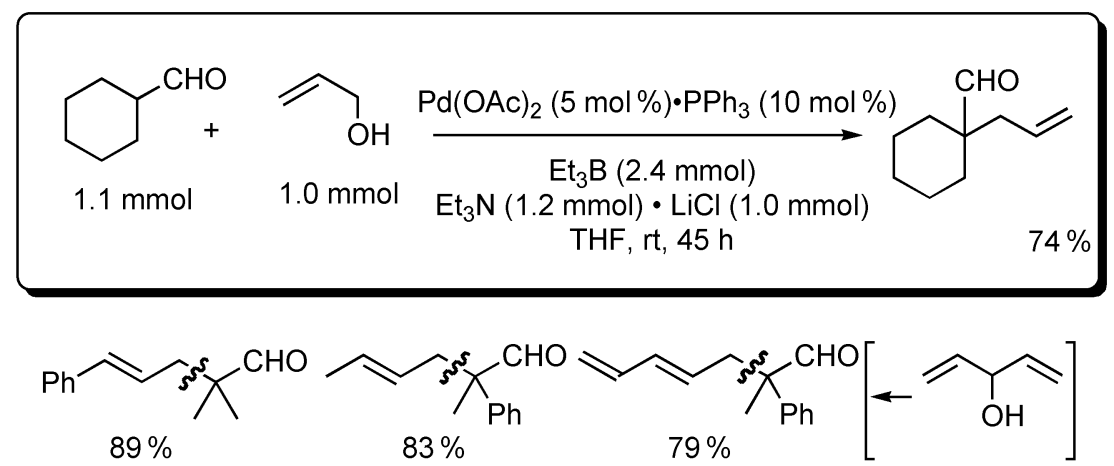

Scheme $9 \alpha$-Allylation of secondary aldehydes with allyl alcohols.

Primary aldehydes showed quite different reaction features (Scheme 10) [15]. For example, hexanal first underwent aldol condensation and provided an unsaturated secondary aldehyde. Then, the thusformed secondary aldehyde reacted as usual to provide the $\alpha$-allylation product. Dihydrocinnamaldehyde and propionaldehyde showed a similar reaction feature, furnishing a 2:1 complex of an aldehyde and an allyl alcohol in reasonable yields.

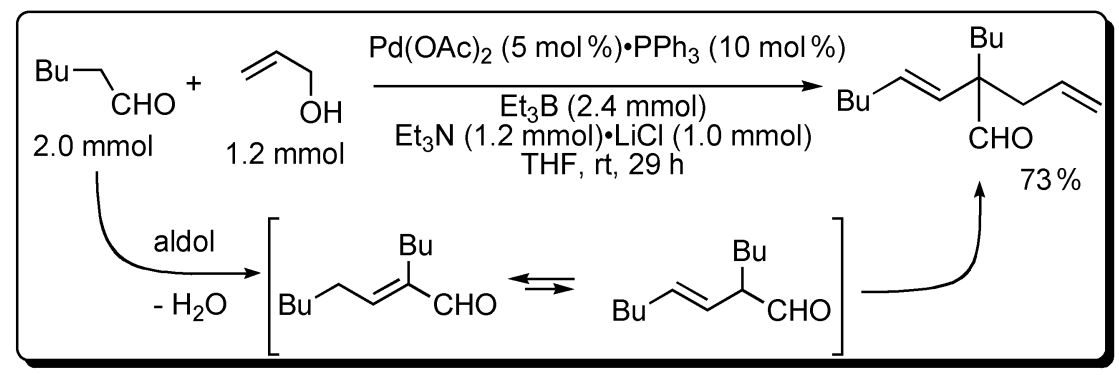

Scheme $10 \alpha$-Allylation of primary aldehydes with allyl alcohols.

Just 10 years ago, we have reported that under Pd-catalysis, cyclic carbonates, such as $\mathbf{1}$, undergoes decarboxylative fragmentation via an oxa-palladacyclopentane intermediate and provides an $\omega$-dienyl aldehyde 2 in $75 \%$ yield (Scheme 11) [16]. The carbonate 1 was prepared by cross-aldol reaction of camphor and acrolein, $\mathrm{LiAlH}_{4}$ reduction, and carbonation with methyl chloroformate. $\mathrm{LiAlH}_{4}$ reduction provided a 1:1 mixture of syn- and anti-diols and only the anti-isomer provided cyclic carbonate, remaining the syn-isomer unchanged.

Recently, we have disclosed that the combination of $\mathrm{Pd}\left(\mathrm{PPh}_{3}\right)_{4}$ and 9-PhBBN nicely promotes $d e$ hydrative fragmentation and provides the same $\omega$-dienyl aldehyde 2 in much better yield (Scheme 11) [17]. This dehydrative fragmentation is much more efficient than our previous decarboxylative fragmentation. According to this new method, we can save one step (carbonation step) and more importantly we can utilize both the syn- and anti-diols for the fragmentation.

In order to promote the dehydrative fragmentation, $\mathrm{Et}_{3} \mathrm{~B}$ turned out to be useless; $\mathrm{Et}_{3} \mathrm{~B}$ underwent hydrolysis readily at room temperature and gave a cyclic borate $\mathbf{3}$ exclusively in a quantitative yield $(\mathrm{R}=\mathrm{Et}) . \mathrm{Ph}_{3} \mathrm{~B}$ showed almost the same results and provided $3(\mathrm{R}=\mathrm{Ph})$. On the other hand, 9-PhBBN (9-phenyl-9-borabicyclo[3.3.1]nonane), nicely withstood hydrolysis and promoted the formation of $\pi$-allylpalladium and the expected fragmentation reaction successfully. 


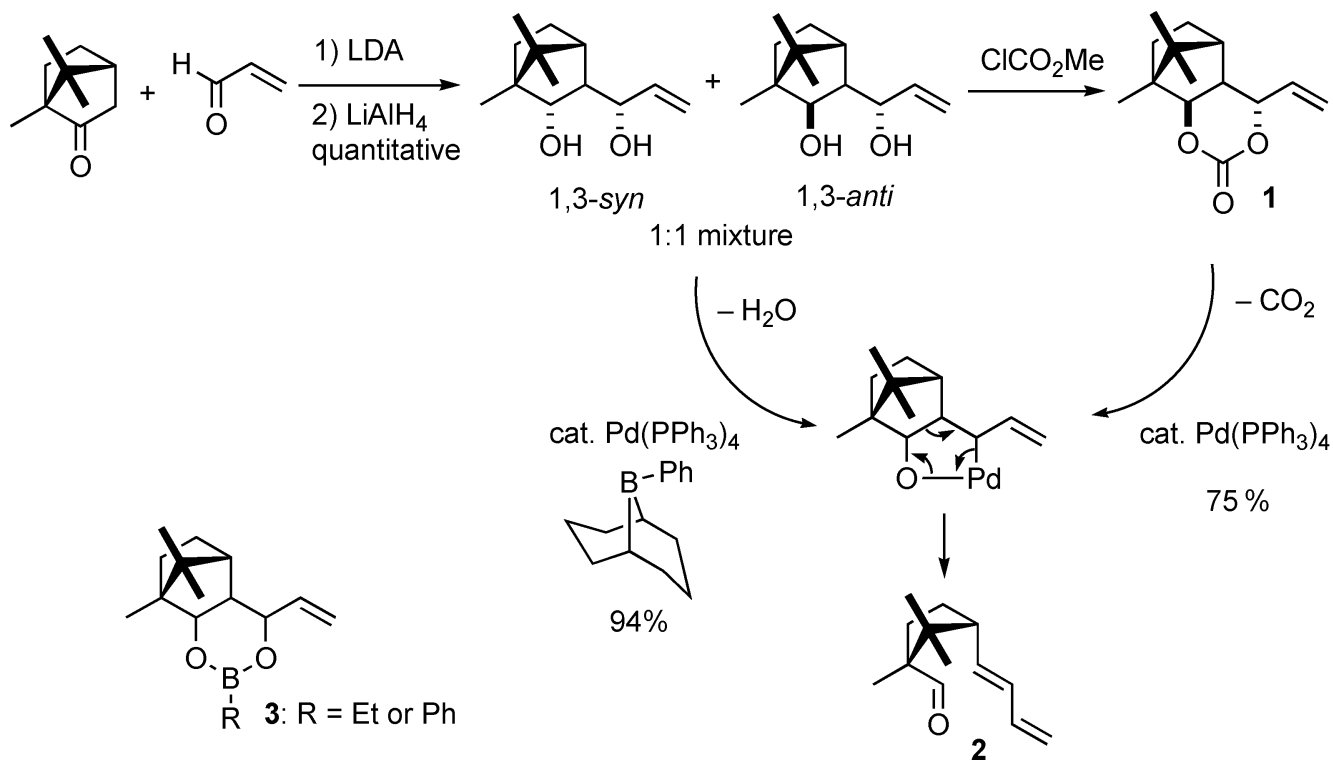

Scheme 11 Pd-catalyzed decarboxylative (via 1) vs. dehydrative fragmentation of 1,3-diol derivatives via a common oxapalladacyclopentane intermediate.

The 1,3-syn-diol shown in Scheme 12 was obtained exclusively in a good overall yield by crossaldol of nopinone and acrolein and LAH reduction. As mentioned in Scheme 11, 1,3-syn-isomer would not form cyclic carbonate owing to steric reasons: steric repulsion between one of the geminal methyl groups and methyne proton, indicated by a double-headed arrow (Scheme 12). And hence, we cannot apply decarboxylative fragmentation to this diol. However, according to the dehydrative method, we are able to obtain the expected product in an excellent yield.

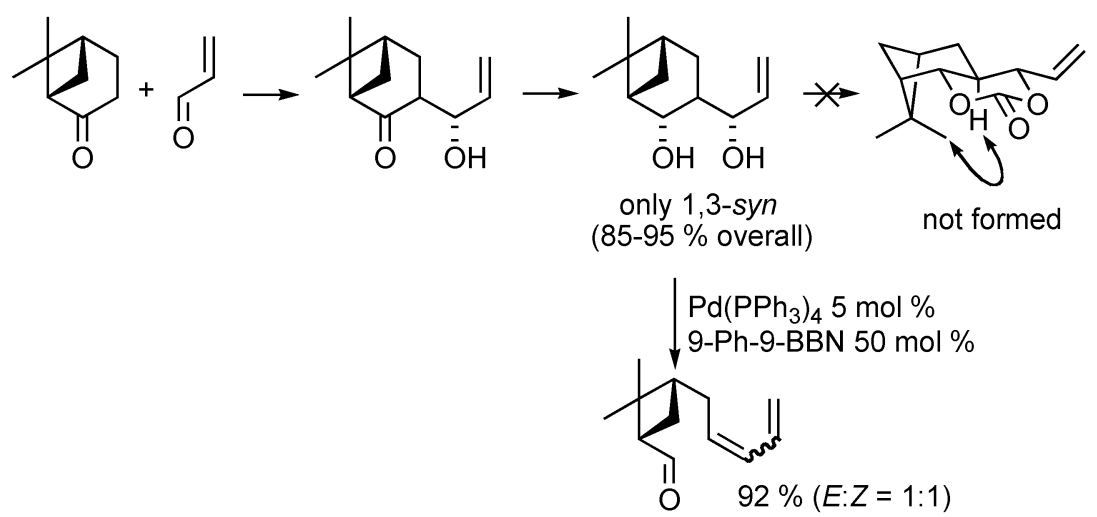

Scheme 12 An example showing superiority of dehydrative fragmentation over decarboxylative fragmentation.

\section{GENERATION OF ALLYL ANION}

As mentioned in Scheme 2, in the absence of nucleophiles, the $\pi$-allylpalladium II may be converted to allylborane, which is known to serve as an allyl anion equivalent [18]. With this idea in mind, the nucleophilic allylation of aldimines was examined (Scheme 13). For example, the aldimine, formed in situ 
from isobutyraldehyde and $p$-anisidine (PMP- $\mathrm{NH}_{2}$ ) by azeotropic removal of water, was treated with allyl alcohol in the presence of $\mathrm{Pd}(\mathrm{OAc})_{2}, \mathrm{Bu}_{3} \mathrm{P}$, and $\mathrm{Et}_{3} \mathrm{~B}$. The expected homoallyl amine was obtained in a reasonable yield [19].

The success of this nucleophilic allylation may owe its origin to the low acidity of $\alpha-\mathrm{H}$ of aldimines (as compared with that of aldehydes) and high reactivity of allylborane toward aldimines. As is apparent from Scheme 13, the reaction is applicable to aromatic aldehydes, unsaturated aldehydes, and secondary aldehydes. However, not surprisingly, primary aldehydes (e.g., dihydrocinnamaldehyde) showed marginal success.

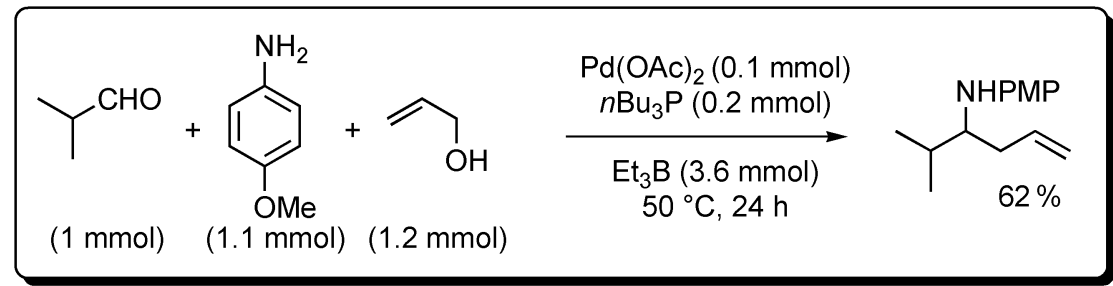<smiles>C=CCC(N)c1ccc2c(c1)OCO2</smiles>

$77 \%(22 \mathrm{~h})$<smiles>C=CCC(/C=C/c1ccccc1)NCCC</smiles>

$72 \%(\mathrm{rt}, 40 \mathrm{~h})$<smiles>C=CCC(NC=C)C1=CCCCC1</smiles>

$72 \%(24 \mathrm{~h})$<smiles>C=CCC(CCc1ccccc1)NPNC</smiles>

$31 \%(18 \mathrm{~h})$

Scheme 13 Nucleophilic allylation of aldimines formed in situ with allyl alcohols promoted by $\operatorname{Pd}(0)-E_{3} B$.

Lactol forms primary aldimine by exposure to $p$-anisidine (Scheme 14). In contrast to the aldimine of dihydrocinnamaldehyde discussed in Scheme 13, this particular primary aldimine behaved nicely and provided the expected homoallylamine in reasonable yield [20]. Furthermore, the reaction showed high stereoselectivity. Especially, $\alpha$-phenylallyl alcohol showed high selectivity and provided syn-isomer exclusively.

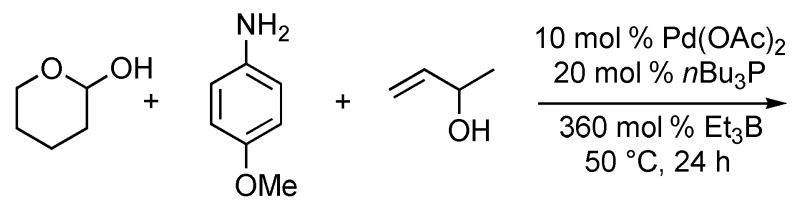

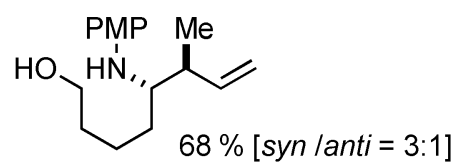
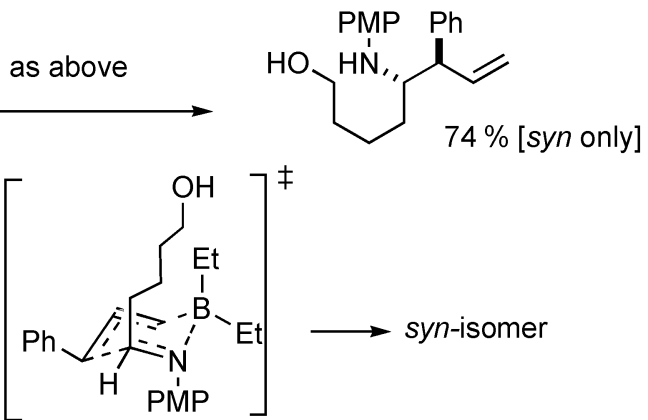

syn-isomer

Scheme 14 Diastereoselective allylation of $\omega$-hydroxyaldimines formed in situ from a six-membered lactol and $p$-anisidine and the most plausible transition state. 
This stereoselectivity may be rationalized by supposing a six-membered chair-like transition state (Scheme 14). This transition state is characterized by an equatorial orientation of phenyl group and diaxial orientation of both substituents of trans-aldimine. Diequatorial orientation of both substituents of trans-aldimine may be prohibited by gauche repulsion between PMP and two ethyl groups on boron.

The reaction can be extended to the allylation of aldimines of ribose and deoxyribose (Scheme 15) [20]. Although the yields are not very good at the moment, this reaction may be synthetically useful, because the reaction can be performed without protection of polyhydroxy functional groups.

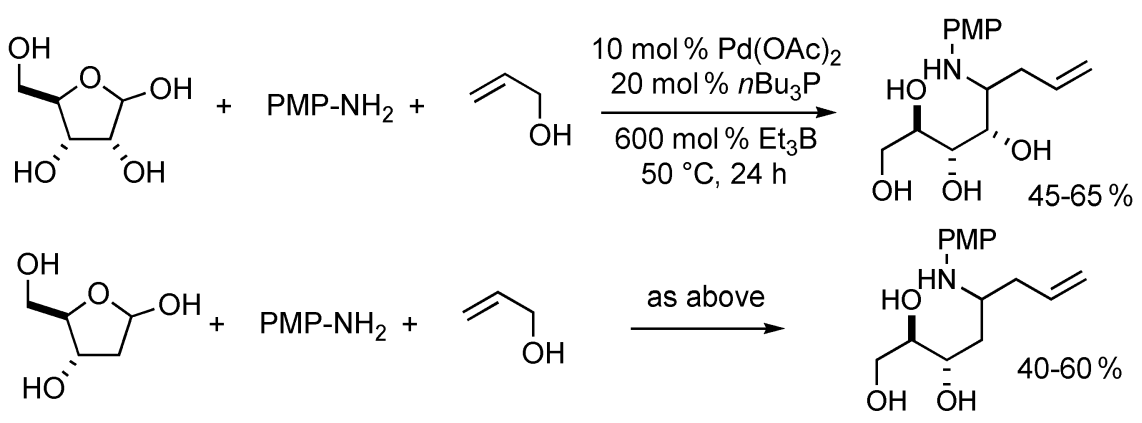

Scheme 15 Allylation of $p$-anisidine aldimines of ribose and deoxyribose.

\section{GENERATION OF ZWITTERIONIC TRIMETHYLENEMETHANE}

As mentioned in Scheme 9, in the presence of $\mathrm{Et}_{3} \mathrm{~N}$ and $\mathrm{LiCl}$, one of the allyl alcohol moieties of 2-methylene-1,3-propanediol serves as an allyl cation and reacts with cyclohexanecarbaldehyde to provide the $\alpha$-allylation product in good yield (Scheme 16).
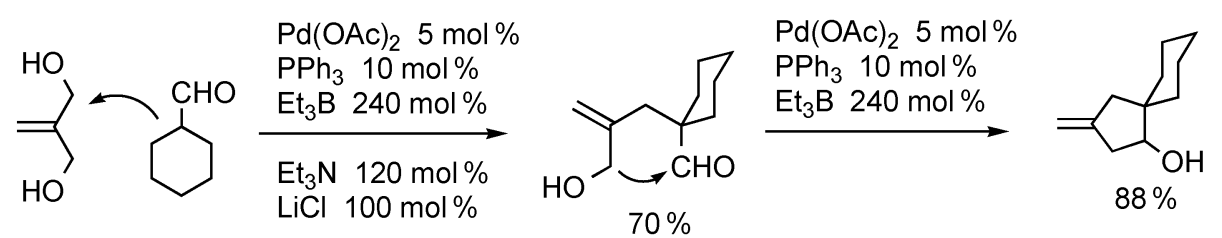

Scheme 16 2-Methylene-1,3-propanediol as a synthetic equivalent of zwitterionic trimethylenemethane I under the catalysis of $\mathrm{Pd}(0)-\mathrm{Et}_{3} \mathrm{~B}$.

On the other hand, in the absence of these additives under otherwise the identical conditions, the remaining allyl alcohol moiety undergoes nucleophilic allylation upon aldehyde carbonyl carbon to provide 3-methylenecyclopentanol in good yield [18,21].

If the $\alpha$-hydrogen of aldehyde is acidic enough, and hence electrophilic allylation proceeds much faster than nucleophilic allylation, we need not use $\mathrm{Et}_{3} \mathrm{~N}$ and $\mathrm{LiCl}$ any more. So, we can perform electronically opposite electrophilic and nucleophilic allylations in one-pot. For example, $\alpha$-phenylpropionaldehyde and $\alpha, \alpha$-diphenylacetaldehyde reacted with 2-methylenepropane-1,3-diol in one-pot and provided the expected products in good yield (Scheme 17). 


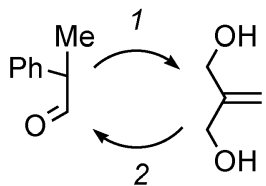

$$
\underset{\mathrm{Et}_{3} \mathrm{~B}(480 \mathrm{~mol} \%)}{\stackrel{\mathrm{Pd}(\mathrm{OAc})_{2}(5 \mathrm{~mol} \%)}{\mathrm{PPh}_{3}(10 \mathrm{~mol} \%)}}
$$

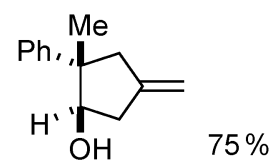<smiles>C=C(CO)CO</smiles>

$\stackrel{\text { as above }}{\longrightarrow}$<smiles>C=C1C[C@H](O)[C@H](c2ccccc2)C1</smiles>

$65 \%$

Scheme 17 Sequential C2 (electrophilic) and C1 (nucleophilic) allylation of secondary aldehydes with 2-methylene-1,3-propanediol.

This amphiphilic activation reaction might remind one of Trost's trimethylenemethane-palladium chemistry [22] and Yamamoto's bis- $\pi$-allylpalladium chemistry [23], especially Trost's, because these two reactions provide structurally similar type products sharing methylenecyclopentane skeleton (Scheme 18).
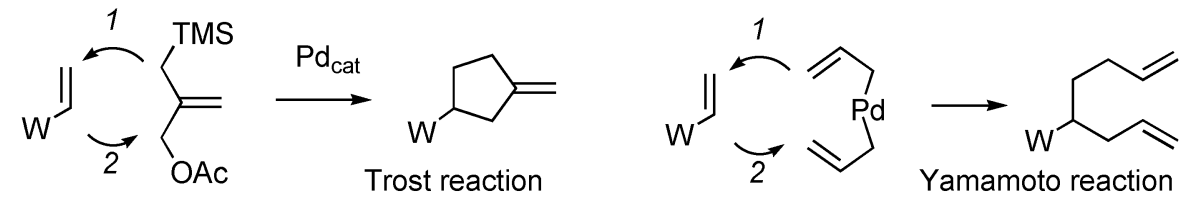

Scheme 18 Sequential nucleophilic and electrophilic allylation developed by Trost and Yamamoto.

From a mechanistic point of view, however, these two reactions are quite different. Our reaction proceeds in order of electrophilic allylation and nucleophilic allylation. Trost's reaction proceeds in opposite order, nucleophilic allylation and electrophilic allylation.

2-Methylene-1,3-propanediol reacts nicely with aldimines formed in situ and provides 2-substituted 4-methylenepyrrolidines (Scheme 19) [24]. In this reaction, allyl alcohol first serves as an allyl anion and then the remaining allyl alcohol serves as an allyl cation. So, the reaction mode of the present reaction is quite similar to that of Trost's reaction (Scheme 18) [25].

It has been well documented that the reaction of aldimines sharply depends on whether the amine moiety is aromatic or aliphatic and also whether the aldehyde moiety is aromatic or aliphatic. In the present reaction, aromatic amines work nicely for the combinations with aromatic aldehydes and aliphatic aldehydes. Aliphatic amines, on the other hand, work nicely only for the combination with aromatic aldehydes. The combination of aliphatic amine and aliphatic aldehydes does not work at all (Scheme 19).

For example, aromatic amines, e.g., $p$-anisidine, worked nicely with aromatic aldehydes, unsaturated aldehydes, and primary and secondary aliphatic aldehydes. The reaction is compatible with hydroxy substituent and chloro substituent and also compatible with heteroaromatic aldehydes. Aliphatic amines (e.g., benzylamine), on the other hand, worked nicely with aromatic aldehydes and unsaturated aldehydes. The reaction with aliphatic aldehydes (e.g., cyclohexanecarbaldehyde) failed to provide the expected product. 


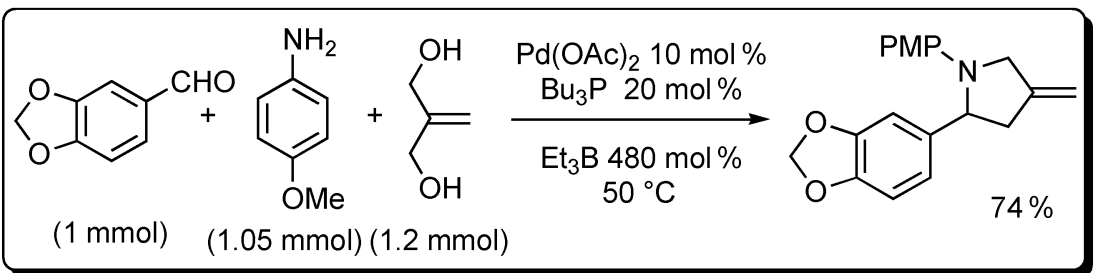

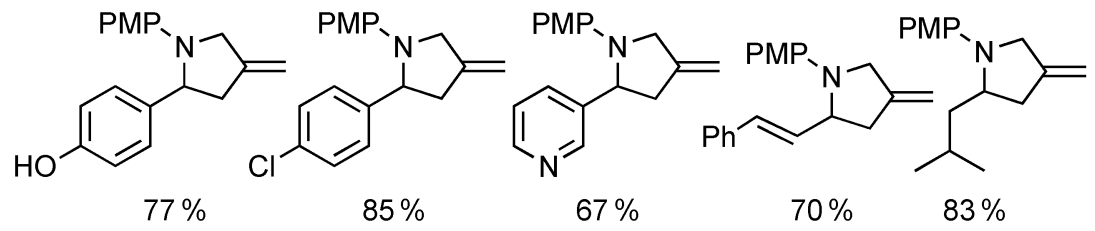<smiles>C=C1CC(C2CCCC(=O)O2)C(C2CC(=C)CN2Cc2ccccc2)C1</smiles>

Scheme 19 Relative reactivity of aldimines composed of aromatic or aliphatic amines and aromatic or aliphatic aldehydes.

This undesirable reaction feature can be settled by a slight modification of the reaction conditions [24]. By using benzyl ether in place of diol and $\mathrm{Et}_{2} \mathrm{Zn}$ in place of $\mathrm{Et}_{3} \mathrm{~B}$, even the combination of aliphatic amines and aliphatic aldehydes showed satisfactory results (Scheme 20).

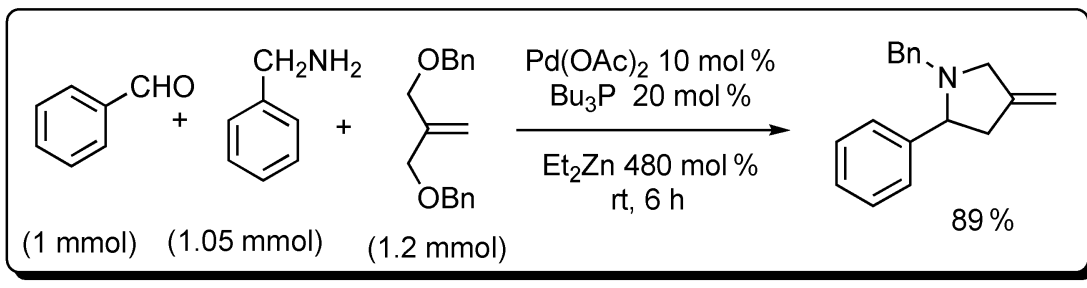<smiles>C=C1CC(c2ccccc2)N([Ga]O[Na])C1</smiles>

$89 \%$<smiles>C=C1CC(c2ccccc2)N([Ga]CC)C1</smiles>

$93 \%$<smiles>C=C1CC(C2CCCCC2)N([Ga]C)C1</smiles>

$97 \%$<smiles>C=C[Ga]N1CC(=C)CC1CCCCC</smiles>

$90 \%$

Scheme 20 Amphiphilic activation of 2-methylene-1,3-propanediol dibenzyl ether under the catalysis by $\operatorname{Pd}(0)$ $\mathrm{Et}_{2} \mathrm{Zn}$.

Under Pd-catalysis, enolates of ketones and esters undergo nucleophilic addition upon vinyl epoxide at the terminal olefinic carbon and provide allyl alcohols in good yields. Strangely, however, no precedents have appeared for the reaction with aldehydes. We have found that even aldehydes nicely react with vinyl epoxide and provide the expected allyl alcohols in good yields under the conditions shown in Scheme 21 [26].

Furthermore, it has been revealed that in the presence of $\mathrm{Et}_{3} \mathrm{~B}$ the thus-formed allyl alcohol undergoes intramolecular nucleophilic allylation to aldehyde to provide 2-vinylcyclobutanol in good yield. 


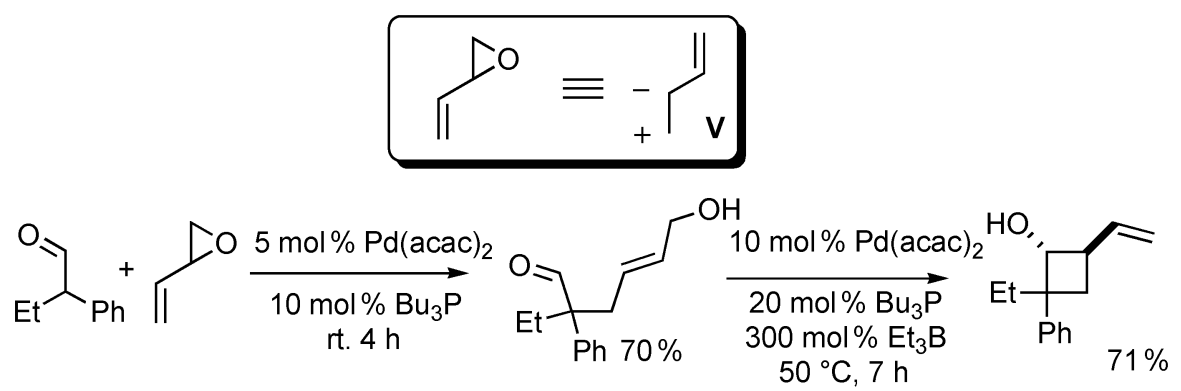

Scheme 21 Vinyl epoxide as a synthetic equivalent of 3-butenyl 2-anion-1-cation $\mathbf{V}$.

These reaction features indicate that vinyl epoxide can be utilized as a synthetic equivalent of 3-butenyl 2-anion-1-cation $\mathbf{V}$ [26].

Generally, the reaction is successful for aldehydes bearing one or two aromatic substituents at the $\alpha$-position. The first electrophilic allylation is promoted by the catalysis of $\mathrm{Pd}(\mathrm{acac})_{2}$ and tributylphosphine, and the second nucleophilic allylation is promoted with the same catalyst in the presence of $\mathrm{Et}_{3} \mathrm{~B}$. These results suggest the possibility of performing these two reactions in one-pot, by adding $\mathrm{Et}_{3} \mathrm{~B}$ after completion of the first reaction. Indeed, the reaction can be performed in one-pot and 2-vinylcyclobutanol was isolated as a mixture of stereoisomers (Scheme 22) [26]. In this particular case, the cis-isomer was obtained as the major product. Interestingly, the isomer ratio changed from the cis-rich one to the trans-rich one during heating at $55^{\circ} \mathrm{C}$.
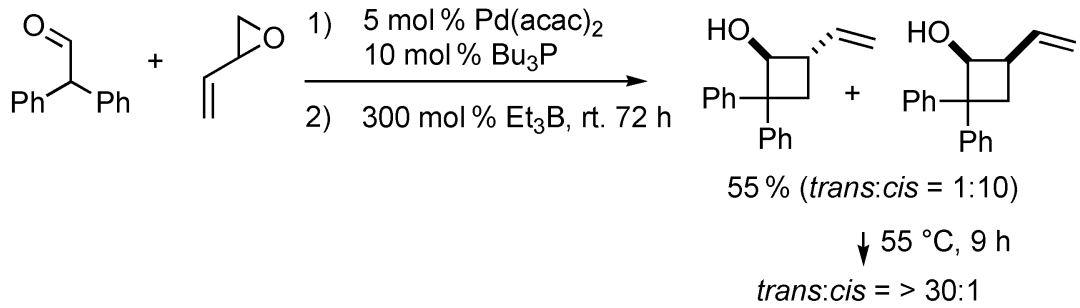

Scheme 22 One-pot activation of vinyl epoxide as a synthetic equivalent of 3-butenyl 2-anion-1-cation and cis,trans-isomerization under the reaction conditions.

These stereochemical outcomes may be rationalized as follows (Scheme 23): an allylborane intermediate may undergo nucleophilic allylation via either cis,cis-cyclooctadiene intermediate or trans,trans-cyclooctadiene intermediate. The cis,cis-isomer is much more stable than the trans,transisomer. So, the reaction may selectively proceed via the cis,cis-isomer and selectively provide $c i s-2$ vinylcyclobutanol under kinetic control. Under thermodynamic control, on the other hand, sterically congested cis-2-vinylcyclobutanol would isomerize to more stable trans-vinyl-cyclobutanol via a sequence of reactions shown in Scheme 23.

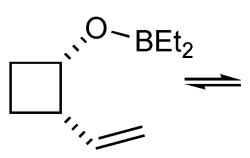

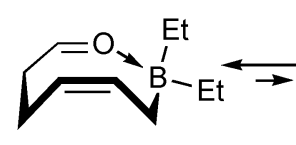

cis, cis

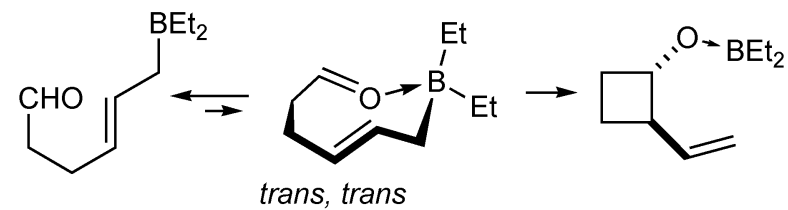

Scheme 23 A rationale for the stereoselectivity observed in Scheme 22. 


\section{REFERENCES AND NOTES}

1. Review: Y. Tamaru. Eur. J. Org. Chem. 13, 2647 (2005).

2. Pd-catalyzed formation of allylboranes from allyl alcohols: V. J. Olsson, N. Selander, K. J. Szabó. J. Am. Chem. Soc. 128, 4588 (2006).

3. M. Kimura, M. Futamata, K. Shibata, Y. Tamaru. Chem. Commun. 234 (2003).

4. (a) Y. Tamaru, Y. Horino, M. Araki, S. Tanaka, M. Kimura. Tetrahedron Lett. 41, 5705 (2000);

(b) Y. Horino, M. Naito, M. Kimura, S. Tanaka, Y. Tamaru. Tetrahedron Lett. 42, 3113 (2001);

(c) M. Mimura, R. Mukai, N. Tanigawa, S. Tanaka, Y. Tamaru. Tetrahedron 59, 7767 (2003).

5. M. Kimura, M. Fukasaka, Y. Tamaru. Synthesis 3611 (2006).

6. J. Herzig, B. Erthal. Monatsh. Chem. 31, 827 (1910).

7. Surprisingly, 2,2,4,4,6,6-hexaallylcyclohexan-1,3,5-trione is a new compound. This may be due to difficult availability of hexa-alkylation products suggested by ref. [6].

8. (a) M. Kimura, M. Futamata, R. Mukai, Y. Tamaru. J. Am. Chem. Soc. 127, 4592 (2005); see also

(b) M. Kimura, M. Fukasaka, Y. Tamaru. Heterocycles 67, 535 (2006).

9. B. M. Trost, J. Quancard. J. Am. Chem. Soc. 128, 6314 (2006).

10. Y. Tamaru, M. Kimura, M. Futamata, Y. Shikina. Manuscript in preparation.

11. (a) M. S. Morales-Rios, O. R. Suarez-Castillo, J. J. Trujillo-Serrato, P. Joseph-Nathan. J. Org. Chem. 66, 1186 (2001); (b) G. H. Tan, X. Zhu, A. Ganesan. Org. Lett. 5, 1801 (2003); (c) F. Hernandez, C. Avendano, M. Söllhuber. Tetrahedron Lett. 44, 3367 (2003).

12. (a) B. M. Trost, E. Keinan. Tetrahedron Lett. 21, 2591 (1980); (b) J. Tsuji, I. Minami, I. Shimizu. Chem. Lett. 1325 (1983).

13. K. Hiroi, J. Abe, K. Suya, S. Sato, T. Koyama. J. Org. Chem. 59, 203 (1994).

14. M. Kimura, Y. Horino, R. Mukai, S. Tanaka, Y. Tamaru. J. Am. Chem. Soc. 123, 10401 (2001).

15. Here, the primary and secondary aldehydes refer to those aldehydes bearing one and two substituents on the $\mathrm{C} 2$ of acetaldehyde, respectively.

16. (a) H. Harayama, T. Kuroki, M. Kimura, S. Tanaka, Y. Tamaru. Angew. Chem., Int. Ed. Engl. 36, 2352 (1997); (b) H. Harayama, M. Kimura, S. Tanaka, Y. Tamaru. Tetrahedron Lett. 39, 8475 (1998); for the Ni(0)-catalyzed fragmentation of cyclic carbonates, see: (c) M. Mori, M. Kimura, Y. Takahashi, Y. Tamaru. Chem. Commun. 4303 (2006).

17. M. Kimura, M. Mori, Y. Tamaru. Chem. Commun. 4504 (2007).

18. Pd-catalyzed nucleophilic allylation of aldehydes with allyl alcohols: (a) M. Kimura, T. Tomizawa, Y. Horino, S. Tanaka, Y. Tamaru. Tetrahedron Lett. 41, 3627 (2000); (b) M. Kimura, M. Shimizu, K. Shibata, M. Tazoe, Y. Tamaru. Angew. Chem., Int. Ed. 42, 3392 (2003); (c) M. Kimura, M. Shimizu, S. Tanaka, Y. Tamaru. Tetrahedron 61, 3709 (2005); (d) M. Shimizu, M. Kimura, Y. Tamaru. Chem.-Eur. J. 11, 6629 (2005).

19. M. Shimizu, M. Kimura, T. Watanabe, Y. Tamaru. Org. Lett. 7, 637 (2005).

20. Y. Tamaru, M. Kimura, M. Hashimoto. Manuscript in preparation.

21. R. Mukai, Y. Horino, S. Tanaka, Y. Tamaru, M. Kimura. J. Am. Chem. Soc. 126, 11138 (2004).

22. (a) B. M. Trost, S. A. King. J. Am. Chem. Soc. 112, 408 (1990); (b) L. A. Paquette, D. R. Sauer, D. G. Gleary, M. A. Kinsella, C. M. Blackwell, L. G. Anderson. J. Am. Chem. Soc. 114, 7375 (1992); (c) D. A. Singleton, B. E. Schulmeier. J. Am. Chem. Soc. 121, 9313 (1999); (d) B. M. Trost, M. L. Crawley. J. Am. Chem. Soc. 124, 9328 (2002).

23. H. Nakamura, K. Aoyagi, J.-G. Shim, Y. Yamamoto. J. Am. Chem. Soc. 123, 372 (2001).

24. Y. Tamaru, M. Kimura, T. Watanabe, T. Tamaki. Manuscript submitted for publication.

25. B. M. Trost, C. M. Marrs. J. Am. Chem. Soc. 115, 6636 (1993).

26. M. Kimura, R. Mukai, T. Tamaki, Y. Horino, Y. Tamaru. J. Am. Chem. Soc. 129, 4122 (2007). 